Concordant and Discordant Construct-Context Dualities as a Framework for Understanding the Choice of Vocational Educational Philosophy of Booker T. Washington

La Shun L. Carroll

University at Buffalo Graduate School of Education

$\underline{\text { lcarroll@buffalo.edu }}$

https://orcid.org/0000-0003-4132-6392

\begin{abstract}
This paper explores the rationale behind Booker T. Washington's vocationalist philosophy of education for the then recently emancipated black population. Through the use of a critical thinking framework, an analysis of remarks from key speeches and his life according to scholars providing Washington's prescriptive argument and rhetoric is undertaken. Despite Washington's intentions, the argument for his vocational approach is demonstrated to be oppressive, myopic, and circular in its logic. The author proposes a framework for understanding the counterintuitive development of vocationalist philosophy based on the dichotomous nature of the human experience's value-construct and context misalignment. Concordant or discordant dualities that result from misalignment are explained and how to reconcile Washington's Vocationalism with opposing the philosophy of W.E.B. Du Bois due to equivalence or consistency of values with theoretical constructs is also discussed.
\end{abstract}

Keywords: $\quad$ Philosophy, Education, Booker T. Washington, W.E.B. Du Bois, Vocationalism 


\section{Concordant and Discordant Construct-Context Dualities as a Framework for Understanding the Choice of Vocational Educational Philosophy of Booker T. Washington}

According to Aristotle who considers it a counterpart of both logic and politics, rhetoric is defined as "the faculty of observing in any given case the available means of persuasion" (Oxford University Press, 2017). To convince an audience, the rhetorician may attempt to appeal to either logos, ethos, or pathos, which are referred to as the three means of persuasion (Rapp, 2010).

As a means of persuasion, an appeal may be made to the "principle of ordering" to which the Greek word "logos" refers (Carroll, 2017). Additionally, persuasion achieved through an appeal to one's ethos results from a successful attempt to target one's sense of character (Oxford University Press, 2017). Likewise, persuading by appeal to pathos occurs as a result of deliberately aiming at one's feelings or emotions (Oxford University Press, 2017). Considering the effectiveness of such appeals, it should not be surprising that these persuasive tactics were employed in the philosophical rhetoric of two of the most significant African-American leaders in history: Booker T. Washington and W.E.B. Du Bois.

It was both the spoken and the written forms of the rhetoric of Washington \& Du Bois that served as vehicles through which they would deliver the content of their prescriptive arguments for the appropriate course down which the country was to head with the recently emancipated black population. Upon careful analysis of their speeches and literary contributions to society, one will notice that the rhetoric outlining their prescriptive arguments not only contained personal beliefs, they also comprised aspects of their educational philosophies.

Through the use of strong-sense critical thinking (Browne \& Keeley, 2015) to evaluate claims and beliefs, this paper considers the rationale behind the philosophy of Washington as it 
pertains to vocationalism as an educational approach. Unlike weak-sense critical thinking used to defend one's present belief, strong-sense critical thinking makes an effort to apply critical skills to evaluate all claims and beliefs, particularly one's, with an opened mind toward revision of one's beliefs and a willingness to abandon his or her flawed arguments (Browne \& Keeley, 2016).

I argue that ideological approaches to education are composites of, and reducible to, what I refer to as the dichotomous nature of human experience. After briefly providing background on Washington and the educational philosophy derived from either a speech or literary work, with the assistance of a critical questioning framework, an evaluation of reasoning and alternative conclusions is conducted. Lastly, the findings are used to describe a framework comprising either concordant or discordant construct-context dualities derived from the lived experience that may explain the basis for the choice of the educational philosophy of Washington.

\section{The Educational Philosophy of Washington}

Although often remembered for their rivalry, there was a period during which Washington and Du Bois corresponded (Adams, 2015). Nevertheless, despite having similar ends in mind for blacks (Dowdy, 1990), each man's ideology would ultimately be that past which the other would not be able to move, which made relating to, and collaborating with, one another an impossibility. While the individual philosophy of education of each man was not without flaw, they both had a unique vision for the correct path that should be taken concerning the manner in which education should be conducted and what it should consist of if successful outcomes were indeed desired for the recently emancipated black population.

Washington believed an industrial education was best. Industrial training consisted of practical skills and trades, hard physical labor such as farming and working with one's hands. He 
also contemplated constructs such as liberty and education, which ultimately became contexts for his life. It did not just happen to him, he fought for it and struggled. Nevertheless, although what he achieved was praiseworthy, Washington's decision to adopt a vocational approach to education to solve the problems of his day was optimistic at best, and naïve at worst. Regardless which one believes was the case, the rationale behind choosing it appeared to be misaligned.

\section{Argument Against Rationale Behind Washington's Choice of Vocationalism}

Washington's vocational approach based on his Mentor, Gen. Armstrong, stressed hard manual labor because it supposedly had a moral and intellectual value that built character (Dowdy, 1990). Unfortunately, I disagree with the rationale for adopting such an approach because the reasoning may be shown to be circular. There is no way to begin without assuming what one tries to prove. If hard manual labor had those values that built character, then what reason would there be for former slaves newly emancipated to agree to endure hard labor once more?

According to this logic, what he thought would be the right training to bring about the change that was sought appeared to be in no significant way different from the conditions when blacks were enslaved. That is, if it were true that newly freed slaves under Washington's vocational approach could build character and discipline through hard manual labor because handwork had physical, intellectual, or moral value as he proclaimed, then upon emancipation, the newly freed slaves should have already acquired the skills and character and not require further hard manual labor as education.

That which Washington had called vocational "education" appears to have been eerily similar to the conditions of slavery, which he ought to have known quite well. Therefore, as an argument for a Vocational philosophy of education, since the students would be starting their 
education having endured hard manual labor under conditions of slavery, and hard manual labor is what builds character and skill, then the emancipated blacks would begin their vocational education with what was to be the result of their training. In other words, this reasoning suffers from unavoidably begging the question, or being circular in its logic (Browne \& Keeley, 2015).

\section{From Circular Logic to a Red Herring in Atlanta}

Among the reasons that Washington supported an industrial/vocational educational philosophy for blacks was his firm belief that white society would only tolerate it and no other form (Lewis, 2014). In his Atlanta Address, Washington remarks the following: "It is important and right that all privileges of the law be ours, but it is vastly more important that we be prepared for the exercises of these privileges. The opportunity to earn a dollar in a factory just now is worth infinitely more than the opportunity to spend a dollar in an opera-house" (Washington, 1895).

Washington makes a valid argument. Essentially, the rhetorical question is "what good is it to exercise the privilege to use one's money if they cannot work to earn any money to use?"

Of course, the answer is "no good at all." Fighting for rights requiring direct or indirect access to what one does not have (i.e., money itself directly or a job where one may earn money indirectly) would be pointless. That notwithstanding, what relevance does the truth of that statement have to the fact that the argument given for vocational training is circular? In other words, the truth of the statement itself does nothing to support or convince anyone. The hard labor being proposed by Washington for emancipated blacks is the equivalent of recommending fish enroll in swimming lessons. Truisms or platitudes such as was uttered by Washington in the Atlanta Address do a fantastic job detracting from the main issue by introducing something irrelevant, which is referred to as the Red Herring fallacy (Browne \& Keeley, 2016). 
Unlike his academic, intellectual rival Du Bois whom Washington felt emphasized an impractical and theoretical education for which there was no immediate benefit, the vocational approach and industrial education provides a skill that could be put to use in a factory where money can be earned with a useful trade. Although it makes complete sense for the moment, the shortsightedness of Washington's position may have been more restrictive than empowering. Perhaps due to the failure to appreciate how any education other than one in industrialism for blacks could lead to work beyond that of physical labor did more to oppress blacks than anything else.

Naturally, Du Bois did not share the same sentiments concerning the appropriate manner in which to educate blacks. As opposed to an industrial approach to education that neglected any substantial form of higher learning, Du Bois believed that it was a strong foundation in classic liberal arts that was going to expedite obtaining equality and opportunities for blacks. His formalized educational philosophy detailed how the process was to occur known as the Talented Tenth (Du Bois, 2014). The Talented Tenth was supposed to be the best, and brightest blacks with impeccable academic credentials charged with leading the masses (Dowdy, 1990). The primary purpose, then, of an educational philosophy such as the Talented Tenth was to provide a pool of the most educated individuals from which potential leaders for blacks would be selected (Shinault, 2014).

Du Bois believed that any progress to be made would be the result of the exceptional few slowly elevating those who were less mentally sharp as far as possible. From this, one of Du Bois' descriptive assumptions would be that the elevation by the educated elite is possible. Such an assumption appeals to emotions and popularity (Browne \& Keeley, 2015). Nevertheless, despite the optimism bias (Browne \& Keeley, 2015), both Washington and Du Bois were guilty 
to a degree of causal oversimplification and confusing cause and effect. That is, education and training are not the only factors contributing to success as an earner or a leader. Also, each may influence the other. Ultimately, I find that both men were also guilty of searching for the perfect solution in that each viewed the other's efforts alone as insufficient and refused to adopt them. However, each man's contribution complemented the other's, and both were, together, responsible for the successes and failures that their efforts experienced collectively as a movement.

\section{Educational Philosophy as Prescriptive Argument}

Given the ethical nature of prescriptive arguments, such as those comprising the aspects of the educational philosophies of Washington and Du Bois that we have considered, it must be an individual's underlying values that influence the reasons justifying them that he or she provides and, therefore, any conclusions derived from them (Browne \& Keeley, 2015, p. 61). A prescriptive argument must be premised on one's taken-for-granted beliefs regarding the relative desirability for competing values, which may be understood as their value assumptions (Browne, \& Keeley, 2015). Such values of which the assumptions consist are the ideas, notions, or concepts that one believes to be worthwhile, which are left unstated (Browne \& Keeley, 2015). That notwithstanding, the order in which one prioritizes values is referred to as one's value preference and is what distinguishes the supporting reasons and conclusions that he or she draws (Browne \& Keeley, 2015).

The values, value assumptions, and value preferences that premised the respective philosophical arguments regarding the education of Washington and Du Bois were the result of their lived experiences. That is, the ideas or concepts believed to be worthwhile, the taken-forgranted beliefs concerning the relative desirability of competing values, and the order in which 
one prioritized them were the result of subjective experience. However, values, assumptions, and preferences may also influence subjective experiences one has. Thus, there exists a dynamism that accounts for the interaction between one's values and his or her experience that imparts the feel of an autonomous, living entity that facilitates rendering it subjective. Together, values, assumptions, and preferences were determined to be responsible for the ideological differences that scholars have identified as being the basis for the antagonism that existed between Washington and Du Bois (Dagbovie, 2007).

Nonetheless, as difficult to discern as they may be from one another, it is crucial to understand that one's subjective experience and the values and value assumptions of the individual doing the experiencing are not necessarily the same or consistent. In other words, although counterintuitive initially, it may be possible for there to exist, two distinct people, each of whom shares the same or similar values, value assumptions, or both, yet oppose one another ideologically because of the subjective experience each may have. Thus, as both causes and effects of the same thing, the influence that values, assumptions, and preferences have on shaping ideology is difficult to deny but may become more evident to the reader when he or she appreciates values, assumptions, and preferences for what I suggest them to either be identical to or consistent with: theoretical constructs.

\section{Values and Constructs: Ideas or Concepts Inferred or Expressed}

A construct is defined as either a directly unobservable mental abstraction that one employs to express an idea or concept (Laerd, 2017), or an idea or concept [which is directly unobservable] that is inferred from observed events (Martella, 2013). Also, values may be understood as the ideas, notions, or concepts that one believes to be worthwhile that remain unstated (Browne \& Keeley, 2015). Thus, whether inferred from observed events, or 
abstractions one employs, the unobservable, unstated ideas and concepts that one holds as values appear to be interchangeable with constructs.

As counterintuitive as it may appear at first glance, although both men's philosophies of education and prescriptive arguments would seem to be starkly opposing, I contend that their underlying values as constructs according to which both Du Bois and Washington subjectively experienced and developed their educational doctrines may not have been different; the context of subjective experience, as the empirical framework within, against, and according to which each man constructed his respective philosophical positions on education significantly differed. A construct-context duality comprised of sameness in values yet contextual differences in which they developed was responsible for their respective ideologies. It is in this manner that one may reconcile individuals' philosophical differences by acknowledging that the values of each person can be similar, or at least consistent with one another.

\section{Equivalence or Consistency of Values and Constructs}

According to the definitions provided, if constructs are unobservable and mental abstractions either used to express ideas or are ideas themselves while values are also ideas that are not directly observed either, then I contend that either values are constructs, or values are consistent with constructs. Moreover, if this is the case, then while constructs are either equivalent or consistent with values and Washington and Du Bois both had similar endpoints as goals for blacks in mind, then the men also had similar values or their values were at least consistent with one another.

Sharing similar or consistent values, it was the contextualized life-experiences of each man that still allowed him to exhibit ideological individuality without compromise. Although they shared similar or consistent values, because the relative intensity with which each man held 
their respective values was dissimilar, both Washington and Du Bois were capable of responding in a unique way concerning prescriptive issues such as those related to philosophy of education. Whatever differences in intensity exist easily translate into particular preferences for a value that one has (Browne \& Keeley, 2015). Also, it is through one's preferences for specific values that lead to the development of a partial ordering. The partial ordering of values based on preferences, which facilitates the process of value prioritization, results in a select group of the highest priority values that are what become one's value assumptions.

Although I maintain that values are either equivalent with constructs, or consistent with them at the very least, this claim in no way precludes individuality or uniqueness in one's philosophy due to the influence that differences in value preferences have on value assumptions in constructing a prescriptive argument or developing ideology. Additionally, relative qualitative characteristics of values as constructs (e.g., when contemplated, why, or how long) that became the context for both Washington and Du Bois I argue contributed to the creation of significant differences that resulted in the divergence of their philosophical viewpoints.

\section{Construct Integration: From Mental Abstraction to Subjective Experience}

Much the same way that Du Bois and Washington were individuals whose existence was a culmination of unique ideas, the experiencing of different events and being treated as distinct people, constructs comprise a variety of dimensions that make them what they are. Examples of constructs include those referring to ideas, people, and events (Laerd, 2017). Constructs referring to ideas, people, and events that certainly played a significant role in the evolution of the philosophical frameworks of both men included racism, equality, discrimination, liberty, and even poverty. Moreover, the emancipated Blacks and the issue of color were vital to the views developed by each man and introduced a social dimension to their constructs. In consideration 
of the nature of the climate in which the two men existed, issues related to morality, the value of life, and (in)tolerance as constructs were likely significantly involved in shaping how, and into whom, each man would evolve.

Despite the undeniable construct similarities that provided the background for the lived experiences of each of the men, actually living the experience resulted in the integration of both men into the very constructs themselves. In this respect, the incorporation into the constructs altered their perspectives such that what was previously an objective, abstract theoretical construct became a subjective, realistic context. Furthermore, as a consequence of the integration that resulted in the formation of a new context, I contend that there was a compelling corresponding cognitive transformation that occurred in both Du Bois and Washington, which was a necessary adaptation if they each were to reconcile their constructs with contexts.

\section{Cognitive Transformation}

For Du Bois, I propose that a significant contributor to his transformation was the experience upon attending college at Fisk in the south. It should be mentioned that, while privileged to be raised in Great Barrington, Du Bois did not himself experience any racial discrimination that had been plaguing the South (Ogden \& Hill, 2014). Thus, when he attended university at Fisk, the maltreatment and discrimination he did experience at the hands of whites broadened his perspective leading to his acquiring empirical knowledge that resulted in a forced integration into the construct of racism, which had theretofore been merely an abstraction (Dagbovie, 2007).

In light of the relative nature of experience, the only thing that could have been worse than getting the deplorable treatment itself that blacks had received throughout their lives would have to be receiving such treatment for the very first time; the contrast alone for the first 
occasion would be the furthest thing from expected that no subsequent occurrence could ever be equally unexpected, as was the case for Du Bois. I contend that Du Bois experienced a "becoming," as he came to know the newfound context of being treated as black imposed upon him for the first time while in the South. Moreover, the formation of bonds with others sharing in this context (Du Bois, 1968) galvanized the transformation that he would ultimately undergo to become one of the greatest leaders in history.

As for Washington, it was his integration after being thrust into the abstract construct of liberty upon emancipation that I argue catalyzed his transformation. While unimaginably unnerving and unfortunate, considering the remarkable potential these men possessed, the experiences prompting their transformations provided both Du Bois and Washington unique and indelible contextual perspectives that were likely responsible for their philosophical divergence and inability to reconcile their ideological differences. That is, to say, transitioning from slavery to freedom would be nearly impossible for someone such as Du Bois to fully appreciate much the same as it would be difficult for a person in Washington's place who did make the transition from slavery to understand the perspective of someone born a free man.

Despite the value-construct similarities, it would ultimately be the contextual differences that were responsible for the apparent divergence of the trajectories observed in the paths the educational philosophies of both Du Bois and Washington had taken. I claim that a reconciliation of their views may be possible if considered from individual perspectives. Based on the resulting person being comprised of both the lived experiences of each person and his or her value-constructs, the perspective that I propose for a framework for comprehension is that of the inherent duality, or dichotomous nature, of which the lived human experience consists.

\section{Dichotomous Framework for Experience: Concordant and Discordant Duality}


By inherent duality or dichotomous nature of the lived human experience, I refer to aspects comprising the essence of humankind's experiences. I propose that there exist two such aspects that each person's experience is comprised of at any given moment. It is these two aspects that account for who a person may be at any particular point in time and what he or she may ultimately become at some future point.

Regardless of whether they are equivalent, or consistent with one another, there is the intangible value-construct dimension comprising the underlying assumptions, ideas, and beliefs held in order according to one's preference. Nevertheless, in contrast with such value-constructs, there also exists that which encompasses the empirical nature of human experience serving as a tangible context for the values that one assumes or believes to be the case. For each person, either the constructs may align with the context within which the values exist; or, both the valueconstructs and contexts may be misaligned. In the former case, when aligned, the constructcontext I refer to as a concordant duality whereas, in the latter case of construct-context misalignment, the result is a discordant duality.

Despite concordant dualities resulting from value constructs aligning with the contexts within which they occur, these value-constructs and contexts need not be caused or influenced by one another, but they may be. Moreover, the constructs and contexts must either be conceptually equivalent or at the least, consistent with one another to result in an overall concordant duality. While there may be only one way to achieve concordance via alignment, there are multiple ways for discordance in duality to occur arising from misalignment of value-constructs and contextual occurrences that may be understood to behave similarly to DNA. 
I thought of as resembling DNA and its respective components, then the viability of the construct-context duality depends on the existence of two strands: each strand may be either value-construct or context. Additionally, because they comprise components that complement one another, given either value-construct or context alone, one can predict what the corresponding strand ought to be comprised of; however, this does not guarantee that it necessarily is or will be as it ought.

When value-construct and corresponding context are as they ought to be, the result is concordant duality. Nonetheless, unlike concordant duality, discordant duality may be thought of as occurring when there is a misalignment of value-construct with a context that results from either a frameshift, deletions, substitutions, or mutations of any component of the construct or context similar to what occurs in the case of damaging errors in DNA. For example, well aware of the dynamism that occurs between value constructs and subjective experiences, one could imagine a disturbance of equilibrium by something like a cold, illness, or amnesia in which either value-constructs change to address the pressing issue of illness but are inappropriate for a context or vice versa. The change could be due to simple shifting of constructs, so another construct substitutes, deletion because of amnesia, or mutation into completely different construct in the case of mental illness. Interestingly, discordant dualities may also undergo modifications to prevent or correct damaging mistakes. That is, corrections may be made via excision or splicing procedures that can repair the errors known or found in one's valueconstructs. Such corrective actions may be self-induced or helped through counseling.

To one's context as an immediate past over which one has no control, repair or corrections may manifest as memory suppression. In this fashion, each person as a whole is dynamic and exists in a state of flux that does not necessarily entail perpetual difference because 
modifications will occur to both constructs as well as contextual aspects. Modification may be simultaneous, asynchronous, and even nullify one another to yield no significant net alteration. Thus, as discordant dualities may be converted to concordant ones allowing oneself to subconsciously reconcile untenable constructs with misaligned contexts or vice versa, concordant dualities are also subject to transformation.

\section{A Noble Fallacy: Washington's Subconscious Reconciliation}

I would argue that Du Bois experienced the most robust construct-context, discordant duality at Fisk when the tone was set for his philosophical worldview to become fixed. Washington's most profound experience of duality discordance I would claim occurred upon transitioning from slavery to freedom. It was then that his value-constructs concerning freedom met the contextual reality of it. In the face of such a discordant duality, subconsciously, Washington's mind fought to reconcile these differences. However, since it would be illogical to assume that solving problems could occur through the implementation of what one does not know, any reconciliation would necessarily have been the result of doing what Washington knew. From this perspective, if one were to attempt to understand Washington's experiential duality and educational beliefs, then, of course, vocational philosophy would make sense; vocationalism was consistent with all that he knew.

Washington claimed his approach could build character and discipline through hard manual labor because handwork had physical, intellectual, or moral value was a composite of idealized value-constructs with context. Where he wanted to take blacks he had been himself; how Washington wanted to get them, there was how he viewed himself as getting where he was. What Washington desired for these people to obtain was the experience of a concordant duality comprising the value-constructs he envisioned. The value-constructs for the people (i.e., 
discipline, character) were the result of a particular context (i.e., hard manual labor), which was based on the world he had known.

As noble and sincere as Washington may have been, his solution was essentially encouraging the perpetuation of the cycle through which they had just passed: enslavement under voluntary conditions followed by emancipation. Thus, it becomes apparent that conditions followed by outcome served as a roadmap for his vocational philosophy if only on a subconscious level. Propounding vocationalism was akin to the conditions of slavery that were experienced; emancipation, I claim, was the subsequent state in which blacks found themselves and Washington likened the character traits obtained and discipline learned having endured hardship to a symbolic manifestation or representation of that freedom from prior captivity. Although it can be empowering psychologically to choose to embrace circumstances beyond one's control, which may have been another subtlety of Washington's approach that may have escaped appreciation, the purpose was to obtain discipline from having persevered through struggle leading to character development.

\section{Logical Fallacy}

Unfortunately, Washington's vision was a classic case of a logical fallacy referred to as post hoc, ergo proper hoc, which means "after this, therefore because of this" (yourlogicalfallacy.com, n.d.). Just stated, while it is true that a causal relationship between two events implies that there exists a sequential or ordinal relationship among them, it is not the case that sequentially or ordinally related events necessarily implies that the particular relationship between the two events is causal. If one of the newly emancipated blacks were to believe Washington's vocationalism, then he or she would be accepting that the conditions of hard manual labor they had just endured was insufficient to bring about the desired character 
improvements it promised yet be expected of their own volition to recommit to another cycle of similar conditions in hopes of achieving a different outcome this time.

It is difficult to decide what was more incredible because either one of two options is correct concerning a relationship that is genuinely causal: cause A yields the same effect B (true causal relationship), or cause A yields different effect $\sim$ B. Thus, if going through with vocationalism comprising hard labor conditions like slavery, then as the true cause A, same effect B results, which means ending up just as they were before beginning vocational training. There would be no point. Otherwise, vocationalism as hard conditions would lead to different outcomes achieving character traits promised, which would imply somehow that slavery was not hard enough manual labor to acquire discipline and improve character. This would be tantamount to self-denial. The fact of the matter is that no significant alteration in outcome would result and to have proposed vocational philosophy of education to emancipated blacks can be seen unfavorably as a way to continue the oppression from which they were emancipated.

\section{Concluding Remarks}

The choice of theoretical framework for the present research was decided upon because it was felt that critical thinking provided the most holistic approach to analysis. Given the sharply contrasting points of contention revolving around the specific aspects of educational philosophy respectively espoused by the two men, their similarities are often and easily overlooked. In researching their positions on the philosophy of education, for every difference indicated by the fact that was uncovered, a corresponding similarity was discovered. The discovery of such similarities required a contextualized analysis of each's educational philosophy, which is what a critical thinking framework provided. 
The contextualized approach to analysis taken prompted consideration of the impact of the context of lived human experience, which guided the inquiry. Ultimately, Du Bois and Washington each developed a p could build moral value as he proclaimed philosophy of education in response to, and a consequence of, the ubiquity and pervasiveness of systematically operationalized constructs including racism that had disproportionately affected Black Americans. Specifically, their respective educational philosophies were used as a means through which they could both, directly and indirectly, target what each concluded were the causes and the effects of their particular values as constructs with which society currently battles more than a century later. 


\section{References}

Adams, N. (2015). The correspondence of W.E.B. du bois and booker T. washington

Browne, M. N., \& Keeley, S. M. (2015). Asking the right questions: A guide to critical thinking(11th ed.). Boston: Pearson.

Carroll, L. (2017). A Comprehensive Definition of Technology from an Ethological Perspective. Social Sciences, 6(4), 126. doi:10.3390/socsci6040126

Dagbovie, P. (2007). Exploring a Century of Historical Scholarship on Booker T.

Washington. The Journal of African American History, 92(2), 239-264. Retrieved from http://www.jstor.org.gate.lib.buffalo.edu/stable/20064182

Dowdy, L. C. (1990). The impact of the philosophies of the Presbyterian Church, U.S.A., Booker T. Washington, and W. E. B. Du Bois on the educational program of Johnson C. Smith University (Doctoral dissertation). Retrieved from ProQuest Dissertations and Theses database.

Du Bois, W. E. B. (2014). The talented tenth. () Fordham University Press. doi:10.5422/fordham/9780823254545.003.0011

Du Bois, W.E.B. (1968). The autobiography of W.E.B. Du Bois: A soliloquy on viewing my life from the last decade of its first century (3rd ed. New York, NY: International Publishers.

Laerd Dissertation. (2017). Constructs in quantitative research | Lærd Dissertation. Retrieved from http://dissertation.laerd.com/constructs-in-quantitative-research.php

Lewis, T. (2014). Booker T. washington's audacious vocationalist philosophy. Oxford Review of Education, 40(2), 189-205. doi:10.1080/03054985.2014.889603 Link

Ogden, W. R., \& Hill, C. B. (2007). The scholar as change agent: W.E.B. Du Bois. College Student Journal, 41(4), 932+. Retrieved from 
http://link.galegroup.com.gate.lib.buffalo.edu/apps/doc/A172977990/ITOF?u=sunybuff_ main\&sid=ITOF\&xid=d $3 \mathrm{fc} 1 \mathrm{~d} 92$

Oxford University Press. (2017). English Dictionary, Thesaurus, \& grammar help | Oxford Dictionaries. Retrieved from https://en.oxforddictionaries.com/

The Atlanta Exposition Address (Booker T. Washington, 1895). (2006). In C. A. Palmer (Ed.), Encyclopedia of African-American Culture and History (2nd ed., Vol. 6, pp. 2428-2430). Detroit: Macmillan Reference USA. Retrieved from http://link.galegroup.com.gate.lib.buffalo.edu/apps/doc/CX3444701370/UHIC?u=sunybu $\underline{\mathrm{ff} \_ \text {main } \& \text { xid }=2528 \mathrm{c} 22}$ 